\title{
Universiteit
}

Leiden

The Netherlands

\section{Language isolates and the spread of pastoralism in East Africa}

Mous, M.P.G.M.; Crevels, E.I.; Muysken, P.C.

\section{Citation}

Mous, M. P. G. M. (2020). Language isolates and the spread of pastoralism in East Africa. In E. I. Crevels \& P. C. Muysken (Eds.), Language dispersal, diversification and contact: a global perspective (pp. 240-249). Oxford: Oxford University Press. doi:10.1093/oso/9780198723813.003.0014

Version:

Publisher's Version

License:

Licensed under Article 25fa Copyright Act/Law (Amendment Taverne)

Downloaded from: https://hdl.handle.net/1887/3243017

Note: To cite this publication please use the final published version (if applicable). 


\section{4}

\section{Language isolates and the spread of pastoralism in East Africa}

Maarten Mous

\subsection{Introduction}

Africa has the longest history of human settlement of any continent and it is very hard to unravel the early periods of its history. One of the big questions in its early history is the beginning and spread of food production in Africa. We can only approach the pre-colonial history of the continent by combining results from various disciplines. In this chapter I discuss what the recent accounts of language isolates can tell us about early African history and in particular about the spread of pastoralism in East Africa. I begin with a more methodological discussion of language isolates in Africa ( $\$ 14.2$ ). In $\$ 14.3$ I turn to the spread of pastoralism in East Africa and its relevance for linguistic diversity, followed by some concluding remarks in $\$ 14.4$.

\subsection{Language isolates and marginalized peoples}

Africa is the continent where mankind developed and most probably also where language developed for the first time. Yet until recently the dominant view of Africa was that it is a homogeneous continent in terms of linguistic diversity. This view was due to the influential classification by Greenberg (1966). His classification of African languages constituted a major breakthrough in terms of bringing ideas and evidence together and reducing argumentation to a purely linguistic level. In the years after Greenberg the dominant image was one of four language phyla in Africa (Afroasiatic, Niger-Congo, Nilo-Saharan, and KhoiSan). The intellectual challenge used to be to establish to which of these four phyla a given language or language group belonged. The intellectual climate has changed and the current view is one of about twenty language families including some language isolates (Dimmendaal 2011; see Map 11.1 in Dimmendaal, Chapter 12 this volume, and Dimmendaal et al., Chapter 11 this volume). The important differences of the current views with Greenberg's classification are that some of Greenberg's higher level groupings, for example Mande and Songhai, did not gain supporting evidence in the decades after his seminal classification and several language groups are now seen as separate families. A case in point is the contested inclusion of Mande, a language family of over sixty languages, in Niger-Congo. Creissels (1981) presents links between Mande and Songhai and questions its membership in Niger-Congo; Vydrin (1994) provides potential morphological evidence for inclusion of Mande in Niger-Congo. Lexicon and phonology of Mande have been reconstructed to some extent and it is evident that little morphology can be reconstructed. The hesitation of inclusion into Niger-Congo is based on the alleged lack of noun classes in Mande (but see Vydrin 1994). The presence of remnants of a Niger-Congo type noun class system of structure and form would form a strong argument for the inclusion of Mande into Niger-Congo (Dimmendaal 2011) but the lack of evidence for a noun class system cannot tell us anything. The great time-depth of the African macro-families makes it very difficult to find strong evidence for high-level relatedness. Another issue is whether Songhai is a branch of Nilo-Saharan or not. Shortly after Greenberg's proposal for Nilo-Saharan including Songhai, Lacroix (1971) published a very critical review of the evidence that Greenberg had provided for this proposal. In the subsequent years Nicolaï $(1977,1984,1990,2003)$ has put forward a series of proposals with different models of linguistic history and suggesting links to Mande and to Afroasiatic as an alternative to Nilo-Saharan. The discussion about the validity of the major language families is more a display of intellectual history in thinking about classification as such but has contributed disappointingly little in terms of new reconstructions. However, freed from the straightjacket of only the four families originally proposed by Greenberg, the floor is open for the suggestion of language isolates and that is what I concentrate on here.

It is in the nature of the concept of a language isolate that proof for being an isolate cannot exist. As a consequence, suggestions for a certain language to be an isolate or unclassified depend on the researcher's attitudes towards what constitutes as sufficient evidence for classification and what constitutes convincing lack of evidence for classification to posit an isolate. There are quite a few languages in Africa that are puzzling and unclassified for a variety of reasons. Proposals for language isolates differ widely from each other, varying between lack of evidence for any classification to likely to be a one-language-family. One type of proposal for an isolate is the mention of a group or a language that we cannot relate to any of the currently known languages. For some putative isolates we have only a name. Gomba in Ethiopia is such a case; the name appears in the literature as an unpublished observation by Hieda that there is a people who once spoke a language called Gomba and consequently shifted to a Nilotic language (Sommer 1992: 346). There are other languages for which we are presumably too late. These languages have only rememberers and their speakers have shifted to another language. Jalaa is a case in point (Kleinewillinghoefer 2001). We have no information on the grammar of Jalaa and this was already impossible to obtain when 
Kleinewillinghoefer collected his data from the last rememberers because all they remembered were individual words. Some of these words cannot be linked to other languages in the area. We will return to the challenge of seemingly unclassifiable lexicon. There are situations similar to Jalaa. In the case of Aasá( $\mathrm{x})$ for example we are also dealing with rememberers who cannot produce sentences and the words that they remember are often difficult to find cognates for (Petrollino and Mous 2011). But enough words in Aasá(x) are clearly Cushitic and contain petrified Cushitic morphology to classify Aasá(x) as Cushitic. Another case is Ongota, which has been replaced by the Cushitic language Tsamakko and there are still a number of speakers (Sava and Tosco 2000, 2003, 2007; Fleming 2006). A lot of the grammatical morphemes and lexicon of Ongota comes from Tsamakko; in addition there are some clear deviant sources, but there is also a considerable amount of lexical material including the pronouns that cannot be etymologized easily. Several classifications have been suggested. The language is already influenced so much by its contacts that it is unlikely that we will be able to reconstruct its history.

There are several cases where we are dealing with (the memory of) a language with a tantalizing set of words that cannot be traced to other languages. Thus, isolates come in different sorts (Hombert and Philippson 2009). A first category concerns those languages for which we simply do not know enough to propose a classification. Some of these languages are extinct or nearly extinct and we will never be able to know their history: Jalaa in Nigeria (Kleinewillinghoefer 2001), Gomba in Ethiopia (previously mentioned), Mpra in Ghana, (M)pre in Ivory Coast, Dompo (all Blench 2007). A second category includes those languages that are difficult to classify because the evidence is conflicting; for example, Ongota has very little morphology that is not Cushitic or Omotic but the personal pronouns point to Nilo-Saharan (Blažek 2007; Savà and Tosco 2007). The morphology of Shabo does not fit with the proposals on lexical grounds that it is Nilo-Saharan (Schnoebelen 2009). A third group of languages are those for which we have sufficient data but neither lexicon nor morphology provide evidence for membership of a known family. After a careful study of all available evidence, Bonny Sands concluded that there is no convincing evidence to classify Hadza with Sandawe, with KhoiSan or with any other African language (family); thus Hadza is an isolate (Sands 1998). Schnoebelen's (2009) discussion of all available evidence for Shabo concludes that Shabo is an isolate, too. BangiMe among the Dogon languages of Mali genealogically is not a Dogon language and it has escaped classification so far (Hantgan 2013; Hantgan and List forthc.). For these three languages there is enough lexicon and grammatical information available that substantiate the claim for being a language isolate.

Roger Blench has been striving very hard to bring all potential cases of languages isolates in Africa to scholarly attention and has stressed that we should see these languages as remnants of pre-Niger-Congo languages (Blench 2013). We can indeed safely assume that the expansion of Bantu and other Niger-Congo language groups have absorbed the languages of people who were there before. But that does not mean that all information we cannot readily interpret provides evidence for these lost peoples. If one is more reluctant with the use of label language isolate, then many of these cases are best seen as unclassified or unclassifiable.

Indeed, ideally these putative isolates can tell us something about people that were replaced by the spread of the large language families such as Bantu, Cushitic, and Nilotic. There are several challenges in that enterprise. A recurrent issue in the study of languages that escape classification is how to deal with the numerous lexical items for which no cognate can be found. This may, for example, simply reflect the poor state of reconstruction of the lexical history of the various language families. We also have to keep in mind that not all lexical innovation is through transfer from another language. It is, however, conceivable that some of the lexical material is a carry-over from languages or language families that have disappeared. In language shift it often happens that part of the lexicon is kept from the original language. Sometimes certain definable parts of the lexicon, often detailed flora and fauna, seem to have a different origin from the rest of the vocabulary. Bahuchet $(1992,2012)$ has proposed that a common specialized vocabulary for flora and fauna among the various unrelated pygmy languages form a remnant of an original pygmy language. Such claims depend on disposing of a comprehensive lexicon for the relevant languages; something which is often lacking unfortunately. Moreover, such a claim requires that the lexicon of the relevant language families to compare with has been reconstructed in sufficient detail. In Africa we are still far from the level of detail of reconstruction that has been reached in Indo-European comparative linguistics, where sets of substrate lexical items from families that no longer survive can be identified.

A complicating factor in the search for the sources of lexical material in the putative language isolates is that the small communities in which these potential isolate languages survive, show a complex and variable make-up of individuals. Very often these communities provide shelter for people who for one reason or another were expelled from their community or have chosen to break with their community. The lexical reservoir of such communities is sometimes extremely varied, in unexpected ways, and of considerable influence since the communities are small.

Another challenge to the use of lexical material from potential language isolates is that the data from languages that are collected in their last stages can be misleading due to the radical changes that happen in the last stages of a language. When collecting lexical material from Aasá(x), we noted tremendous lexical variation in form and meaning among the rememberers. This is typical for situations of language loss (Petrollino and Mous 2011).

Language isolates are not the only possible places where the lexicon of previously existing languages and language families may have survived. We have to 
keep in mind that there are many more instances of remnants of lexicon for which we have no cognates. Sometimes secret languages, ritual languages, and initiation languages harbor lexical data that are clearly from a different language and sometimes we do not know the sources of their lexicon. Special registers are often prone to lexical manipulation and hence cognates of lexical items are often no longer recognizable (Mous 2003a). In other words, there are many instances of lexical items to be accounted for which one could imagine that they point to a lost language that is not part of one of the known present-day families.

\subsection{Spread of pastoralism in East Africa and its relevance for linguistic diversity}

In this section I discuss the possible effects of the emergence and spread of pastoralism on the linguistic diversity in East Africa (present-day Kenya and Tanzania) in order to investigate what language isolates and the languages of other marginal groups can tell us about this early period in history.

When we think of food production agriculture comes to mind first. However, I will not discuss agriculture much in this chapter. The main reason is that there is very little known about the pre-Bantu spread of agriculture into Kenya and Tanzania. Pastoralism in East Africa may have been relatively late but it was much earlier than agriculture. There is no direct archeological evidence of early farming among pastoralists. Archeologists assume the presence of agriculture in the period of the Pastoral Neolithic but the evidence is indirect. Robertshaw and Collett (1983: 68) 'conclude that agriculture must have existed then, on the basis of polished and ground stone artefacts and the agricultural potential near the sites of the Pastoral Neolithic in East Africa. Historical linguistic evidence strongly suggests that the people who once spoke South Cushitic in East Africa and those who spoke South Nilotic knew agriculture (and pastoralism) on the basis of the presence of reconstructed terms in proto-South Cushitic and protoSouth Nilotic (Ehret 1971, 1980; Kiessling and Mous 2003). Lane et al. (2007) show that changes in food production and food processing are changes that are best studied in a local context and are more complex than chronological strata linked to language families and migration.

The situation in East Africa is different from that in Eurasia in that pastoralism developed before agriculture. Archeology shows that cattle have been domesticated in Central Sudan around 9,000 B P (Wendorf and Schild 1998). Later goats, sheep, and the new humped Zebu cattle were introduced in Africa through contact with the Middle East (Hanotte et al. 2002). Some 5,000 years ago sheep and goats were present in East Africa (Barthelmé 1985, cited in Clutton-Brock 1993: 69). Humped cattle were first attested in Egypt around 1500 BC (CluttonBrock 1993: 67). Marshall and Hildebrand (2002) argue that the motivation for hunter-gatherers to domesticate cattle could have been to have dependable access to meet in circumstances when the need arose, as in ritual ceremonies for example. Central Sudan hosted wild cattle at that time $(9,000$ B P) and these animals were becoming scarcer due to changes in the climate. In order to be sure to have access to meat when necessary for crucial celebrations, hunter-gatherers needed to keep animals. Pastoralism spread first at the same latitude and only later (around 6,000 B P) southward (Marshall and Hildebrand 2002). The expansion to the south into East Africa was difficult because it was new terrain where there were no existing links with hunter-gatherer bands. Links with other groups such as huntergatherers are essential for pastoralists for times when cattle are diminished due to epidemics of cattle disease. Cattle diseases were a major challenge in areas where there were large herds of related animals (Gifford-Gonzalez 1998, 2000). Pastoralists reached Kenya and Northern Tanzania about 4,000 в Р and after 3,000 B P there existed a patchwork of pastoralists and hunter-gatherers (Ambrose 1984; Marshall 2000).

The early east African pastoralists combined herding with hunting. Specialization in herding and dependence primarily on cattle occurred much later, roughly 2,000 years ago (Marshall 1990). In the same period East Africa continued to host hunter-gatherer populations. Herding does not interfere with hunting and gathering practices, not as much as agriculture does. The abundance of game in East Africa made herding less attractive as an alternative to hunting because herding is time consuming and requires constant attention. This may be a reason why herding was adapted relatively late in East Africa (Marshall and Hildebrand 2002; see also Mous 2017). Two types of hunter-gatherer societies are often distinguished: delayed-return and immediate return (Woodburn 1982). The latter consume immediately what they hunted and gathered; the former have ways of storing food. For them the step to pastoralism is easier. The symbiosis of delayed-return hunter-gatherers with herders was an important factor in Central Sudan for the development of pastoralism (Marshall and Hildebrand 2002). Delayed-return societies show more organization and are better equipped for food production. Such relations between pastoralist groups and hunter-gatherer societies probably also developed in Kenya and North Tanzania. Symbiosis between hunter-gatherer groups and herders has been a common phenomenon in East Africa up to today.

Many (possibly as many as a hundred) of these symbiotic hunter-gatherer groups (often named 'Dorobo' in East Africa) have been reported for East Africa. Most groups of hunter-gatherers in present times in East Africa are such Dorobo and live in an uneven social relationship with a pastoral group, mostly Maasai. The histories of these groups show what effect this relationship can have on language. The Dorobo groups tend to shift to the language of their masters. Winter (1979) has described in detail how the Aasá(x) shifted to Maasai and that a crisis among the Maasai due to an epidemic of rinderpest was a crucial factor. In that period the Maasai survived in the Aasá(x) dwellings and imposed the Maasai language (that the Aasáx already spoke) to a point of no return. Another example of a Dorobo group shifting their language is nrovided by the Yaaku1 Thev oradually 
adapted to the lifestyle of their masters, to Maasai culture and values, which included keeping cattle (cattle as part of bridewealth) and leaving their caves (Cronk 1989). They decided to give up their language in favor of Maasai (Brenzinger 1992). Yaaku and Aasá(x) thus are Cushitic languages that have died out because of a shift to Maasai by Dorobo hunter-gatherer groups. The model suggests that the (Cushitic) languages spoken by these hunter-gatherers were acquired by them in a similar fashion in an earlier stage. The model also suggests that in early times as well pastoral societies, in situations of distress such as suffering from cattle loss due to diseases, imposed their languages on hunter-gatherers. This was particularly the case in the period when pastoralists had specialised in herding and had become dependent on their cattle for subsistence (Marshall 1990). We can assume that many languages of former hunter-gatherer groups disappeared in this way. The question is whether something of their former languages is traceable. In the case of Dahalo, a Cushitic language spoken by former huntergatherers, the presence of a click has been considered as suggestive of a former KhoiSan language (Nurse 1986). Though there was the recent shift of Aasá(x) to Maasai, there is evidence for the survival of some fauna and hunting terminology among those people who are still identifiable as being of Aasá(x) origin (Petrollino and Mous 2010). There is no indication as yet for a surviving hunter-gathering lexicon in the present-day languages of East Africa, parallel to the proposed Pygmy substrate (Bahuchet 1992, 2012).

How common are such specialized bands in East Africa? Wambua (2012) provides a list of sixty-seven Dorobo groups in Kenya based on earlier lists by Van Zwanenberg (1975) and Ng'ang'a (2006). Rottland and Vossen (1977) put some order in the chaos of names of these Dorobo groups. Banti (1997) assembled an impressive list containing more than twenty names of low-caste groups among the Somali and the Oromo; some are hunter-gatherers, some are occupational groups. As noted, many of the Dorobo or hunter-gatherer groups in East Africa speak the language of their dominant neighbors, mostly pastoralists and mostly Maasai. Relations of hunter-gatherers with agriculturalists exist as well. Hunter-gatherers can be related to more than one dominant partner. The Okiek of Kenya, for example, are partly oriented to the Maasai and partly to the Kipsigis Kalenjin (Distefano 1990).

Available data strongly suggest that there was much more linguistic diversity in East Africa 1,000 years ago. Many societies in East Africa have traditions of supplanting an original population. For example, among the Taita of Kenya traditions recount of two earlier inhabitant groups in the area; one group being agricultural pastoralist, the other hunter-gatherers called wasi (Merrit 1975; Liszka 1974). Wasi is a common Bantu term referring to 'original inhabitants' (Nurse 1979: 390-2). The Pare in Tanzania also speak of an earlier people vasi (Kimambo 1969: 271). Among the Shambaa and Ngulu people of Tanzania there is the myth of a hunter called Seuta (from uta 'bow') becoming their first chief (Feierman 1974; Walz 2010). Relationships between agriculturalists and original inhabitants are different from those between hunter-gatherers and pastoralists. Agriculturalists dig in the land where the dead of the former inhabitants are buried and they fear the reactions from those spirits. A crucial factor. is that the agriculturalists consider "their own feelings of the sanctity of land ownership and the dread of departed spirits bearing ill feelings." as Distefano (1990: 48) puts it describing how the Kikuyu thought of original Athi (= W-asi) land. Agriculturalists need the huntergatherer group that they see as original controllers of the land for ceremonial purposes. It is clear that hunter-gatherer and pastoralists relations were abundant and this often resulted in shift to the dominant pastoralist's language. The success of sedentary agriculturalists and pastoral-agriculturalist absorbed hunter-gatherer and other original occupants of the land by integrating them into their society, again resulting in language shift. Most instances of language shift are complete and eventually leave no trace of the former language. We can only hope to find some traces of earlier languages after a more extensive collection of (specialised) lexicon and lexical reconstruction of all levels of the language families involved.

It is too simple, however, to see the East-African hunter-gatherer groups of the present and the recent past as remnants of old hunter-gatherer societies. Chang (1982: 271) argues that hunter-gatherer groups "consisted largely of disenfranchised pastoralists and farmers." This may be a too direct interpretation of the local representation of Dorobo as impoverished Maasai, but it is important to keep in mind that many such groups define themselves by occupation rather than by descent and these groups often (temporarily) host individuals from other ethnic groups. People go back and forth between food production and hunting/gathering, as is shown by Astuti (1995) for the Vezo fishermen of Madagascar.

It is also important to keep in mind that not all hunter-gatherer communities live in symbiosis with a food producing group. The Hadza (who speak an isolate) and Sandawe (who speak a Khoi language) of Tanzania are not in servant relation with another group. These are also communities that have kept a separate language for a long period and did not shift to another dominant language. In fact, several clans among the Sandawe consist of neighboring farmers that entered Sandawe society (Rimi/Nyaturu and Alagwa). There is strong tendency to language shift among hunter-gatherers but only for those that live in symbiosis with another community. The agriculturalist and pastoralist communities of East Africa do not give up their language so easily but their languages are in intense contact with other languages. For the pastoralists of East Africa cattle is central to their culture and to their identity. This translates to a strong attachment to their language. The recreation of a language of their own by the Ma'á/Mbugu can be understood as motivated by their need for a strong marker for their identity as cattle people and as different from the surrounding agriculturalists (Mous 2003b). In sum, we cannot simply equate manner of food production with language, with a certain culture, and with certain people but some of these relationships are stronger than others. The languages of hunter-gatherers are very often those of their former masters but only if 
they have such a symbiotic relationship. For other hunter-gatherer communities their language may go back to pre-food production times. Radical pastoralists have been the most powerful societies in the recent past in East Africa and have absorbed smaller groups but not given up their language. Agriculturalists (often with cattle) have either prospered or suffered economic challenges and depending on that, may have shifted to another group and another language, or not.

The current linguistic and cultural situation in East Africa thus can be understood in the light of spread of pastoralism in the area. We know about this early spread of pastoralism from archeology. Commonly three types of archeological cultures are recognized in East Africa. Two of them, Savanna Pastoral Neolithic and Elmenteitan, are associated with South Cushitic and South Nilotic respectively (Ambrose 1982, 1984). Both speakers of South Cushitic and South Nilotic must have entered the East African scene from the north where their closest relatives still live and before the arrival of the Bantu. Both South Cushitic and South Nilotic are associated with pastoralism and with agriculture. From the reconstructed lexicon for these groups (Ehret 1998 and references therein; Kiessling and Mous 2003) one may conclude that they developed agriculture without Bantu influence. The third type of archeological culture is called the Eburan hunter-gatherer culture. There are two different languages and language families still spoken in East Africa: Hadza and Sandawe. The Hadza are hunter-gatherers; the Sandawe once were.

\subsection{Concluding remarks}

Obviously, it is difficult to link archeology, language, and people. One of the challenges is that absolute dating in historical linguistics is impossible. Glottochronology has been shown to be unreliable because the rate of replacement in vocabulary is not constant. On the contrary, there are huge fluctuations in the rate in which vocabulary is replaced as this can be linked to radical changes in cultural relations or a crisis in the language group. Despite this fact a rough chronology is often proposed; see for example Ehret (1974). In the case of East Africa the dominant hypothesis is that Cushitic language arrived there before the Nilotic ones. This 'fact' helps in linking the Pastoral Neolithic culture with South Cushitic and the Elmenteitan culture with South Nilotic At the time when these links were proposed South Cushitic was seen as one of the primary branches of Cushitic and thus possibly very old. There has been a major revision in the subclassification of South Cushitic from primary branch to a sub-branch of East Cushitic (Hetzron 1980) but surprisingly this has not led to any revision of dates for the presence of South Cushitic in East Africa by influential scholars like Ehret who do accept the revision in classification and are most quoted for a chronology of language groups in East Africa.

Human genetic research has the potential to establish the link of archeological culture and language with people. It is however difficult to establish connections between an individual's genes and recognizable ethnolinguistic groups. This challenge is bigger in Africa because the continent displays the highest genetic diversity, being the continent where mankind developed. Also, because of the prolonged contact of people and languages, it is difficult to find clear markers for ethnic groups. There are, however, some recent proposals of how genes spread from north to south through East Africa. These movements are suggested to be linked to the spread of cattle and linked to developments in East-African pastoralism. Most likely these movements do not point to the earliest spread of pastoralism in the region but rather to subsequent innovations in animal husbandry and pastorai culture. Pickrell et al. (2014) use a Eurasian marker to show the entry of Ethiosemitic speakers into Eritrea-Ethiopia around 3,000 years ago and show how these genes eventually spread in roughly 1,500 years to arrive among the Khoisan peoples in Southern Africa, with admixture. They do not speculate on which peoples were involved in that spread. Henn et al. (2008) propose a spread of people from East Africa to Southern Africa about 2,000 years ago (with a much larger uncertainty due to a different method), and link this to the spread of cattle from East Africa to Southern Africa ${ }^{1}$ and they do propose a specific people who were involved: speakers of a Southern Nilotic language (linked to Elmenteitan archeological culture) and more specifically Datooga/Barabaig in present-day northern Tanzania who have the highest proportion of the genetic marker in question (of those groups for which data were available). ${ }^{2}$

\section{Acknowledgments}

I would like to thank Pieter Muysken and Maarten Kossmann for comments on an earlier version of this chapter. I thank Jean-Marie Hombert for his stimulating me to write this chapter.

${ }^{1}$ See Smith (2005) for archeological arguments for this eastern route for the introduction of cattle in Southern Africa.

${ }_{2}^{2}$ The additional cultural historical arguments that they propose for suggesting a link to Datooga are not entirely convincing and show the challenges of establishing such links. One argument is Ehret's (1998) proposal for Central-Sudanic (encompassing Southern Nilotic) loans in Khwe. Güldemann (2008a) argues that these putative loans are unlikely. A second argument is the similarity in style in pottery between Bambata-ware and the Elmenteitan culture in Ngamuriak for which they refer to Marshall (1990) who discusses Ngamuriak pottery at length but does not suggest any link to Bambata, and to Smith (2005) who wonders "Is Bambata the connecting link, as suggested by Ehret?" but also does not argue for it on the basis of similarity in ware. A third argument is the historical fact that a group of Datooga/Barabaig (Southern Nilotic) entered Sandawe society to become the Alagwa clan. Their reference is Newman (1970) who refers to a then forthcoming article by Ten Raa. (1986) article, however, links the entry of the Alagwa clan among the article by Ten Raa. Ten Raa's tant introduction of cattle) to their South Cushitic neighbours (called Alagwa) and not to the South Nilotic Datooga/Barabaig. 


\title{
Language Dispersal, Diversification, and Contact
}

\author{
A Global Perspective \\ Edited by \\ MILY CREVELS \\ PIETER MUYSKEN
}

